\title{
Seismic performance of deep excavation restrained by guardian truss structures system using quasi-static approach
}

\author{
Mahdi Maleki ${ }^{1} \cdot$ Ali Nabizadeh $^{2}$
}

Received: 9 September 2020 / Accepted: 23 February 2021 / Published online: 4 March 2021

(c) The Author(s) $2021 \quad$ OPEN

\begin{abstract}
The control of deformation and stability of the deep excavation walls under seismic and static loads is one of the most important issues in geotechnical engineering. Therefore, in the present study, using the finite element method and taking into account Hardening soil's behavioural model, the effect of different parameters affecting the performance of the deep excavation walls with the guardian truss structures using quasi-static analysis and its comparison with static analysis has been performed. According to the most important results, increasing in the geotechnical parameters of soil such as cohesion, friction angle and elastic modulus will reduce the maximum horizontal displacement in the vertical trench wall. Besides, the maximum settling in the adjacent ground and the maximum swelling in the bottom of the excavation will be reduced. In this way, the improvement in soil resistance parameters will increase the safety factor. Conversely, by increasing the horizontal distance between the trusses, the maximum horizontal displacement and the maximum settling in the adjacent ground and the maximum swelling in the bottom of the excavation will increase and the safety factor will be reduced. Also, the findings from this research show that by increasing the horizontal seismic acceleration coefficient $\left(K_{h}\right)$ and as the construction stages progress, the maximum horizontal displacement of the wall, the maximum settling of the adjacent ground of the wall and the maximum swelling on the bottom of the trench increase and the safety factor will decrease. As well as, the results obtained from the quasi-static seismic analysis of the vertical trench restrained by the guardian truss structure such as the maximum horizontal displacement of the vertical trench wall and the maximum settling in the adjacent ground and the maximum swelling of the bottom of the excavation are much more than the static analysis.
\end{abstract}

Keywords Finite element method · Quasi-static seismic analysis · Static analysis · Guardian truss structures

\section{Introduction}

With regarding urban spaces spread and increasing the rate of building construction in residential areas, there has been an increasing demand for utilisation of underground spaces. Therefore, the safety of surrounding buildings in urban areas by the design of braced excavations has become a serious concern for adjacent residents.

When a portion of soil excavated, significant changes induce both in stress and strain fields of the soil around them and, therefore generating permanent displacements to adjacent structures and infrastructures [1, 2].

For designing and constructing a system of supporting excavation structures, one of the most important issues is predicting their performance before the beginning of construction. In most studies, the retaining wall system behavior and performance analysis was done according to two-dimensional analysis using the static and quasi-static methods that the quasi-static method is one of the methods of seismic analysis of structures and the first method

Ali Nabizadeh, Ali.nabizadeh@sru.ac.ir; Mahdi Maleki, mahdi1793@aut.ac.ir|'Department of Civil Engineering, Amirkabir University of Technology, (Tehran Polytechnic), Tehran, Iran. ${ }^{2}$ Department of Civil Engineering, Shahid Rajaee Teacher Training University, Tehran, Iran. 
by which seismic design was possible. The theoretical basis of this method is the principle of De Allembert, which states that when a structure in the amount of $A$ is accelerated, the effects of this vibration on the upper structure are $(A / g) \times W$ in the opposite direction of acceleration. Therefore, the quasi-static coefficient $K$ is as follows:

$K=(A / g) \times W$

which $g$ is the acceleration of gravity and $W$ is the weight parameter. In the seismic analysis of the trenches, with this method, instead of applying cyclic earthquake loads to the model, they are eliminated and the forces generated by the earthquake In the form of static forces $F$ as follows:

$F=(K \times W)$

which $(K)$ the is pseudo-acceleration coefficients that for horizontal and vertical directions $\left(K_{h}\right.$ and $\left.K_{v}\right)$ is determined both as a coefficient of gravity acceleration and their direction is determined in such a way as to create the most critical state. Parameter $W$ is the weight of the structure and in both horizontal and vertical directions, in the form of vertical inertial forces $\left(F_{v}\right)$ and horizontal inertial forces $\left(F_{h}\right)$ which can be obtained as follows:

$F_{h}=K_{h} \times W$

$F_{v}=K_{v} \times W$

These forces are applied to the center of the failure wedge and the problem is statically examined. An earthquake can put the slipping mass under the influence of both vertical and horizontal quasi-static forces, but in most earthquakes the maximum vertical acceleration is less than the maximum horizontal acceleration there for $K_{v}<K_{h}$ and as a result $F_{v}<F_{h}$ and the vertical quasi-static force will have less effect on the stability coefficient, which is why, in quasi-static analyzes, the vertical acceleration is usually neglected.

The similarity of the quasi-static method with the static method used by a geotechnical engineer is because its easy to understand and calculations. The quasi-static method is used for stability and determination of safety factor of circular and non-circular linear sliding surfaces of slopes.

In recent years the seismic performance of deep excavations has been investigated by many researchers, Rouainia and Panayides [3] investigated the performance of a deep excavation using the finite-element method. Castaldo and De luliis [4] using the finite element method studied the effect of deep excavation on the amount of seismic damage in a structure. Gaxiola-camacho et al. [5] investigated the seismic performance in structures excited by dynamic loading in the time domain. Maleki and Mir Mohammad
Hosseini [6] investigated the performance of a deep excavation restrained by anchorage system using quasi static approach.

A slope is an artificial or natural depression on the earth's surface. Soil stability is endangered when excavating soil. One way to keep the soil stable during excavation is to remove the soil at an angle to a horizontal level. This method maintains soil stability. If geometric and geotechnical characteristics of the earthen slope are such that it can not resist soil gravity or failure, the earthen slope after excavating and eliminate the resist forces in the slip surface will slip and move downwards.

From the static point of view, slip occurs when thrust forces overcome the forces of resistance that derive from the shear strength of the soil at the sliding surface [7]. In controlling the safety and stability of the slope, the shear stresses created along the most critical and most likely slip surface should be calculated and compared with the shear strength.

It is necessary to use an appropriate retaining wall or bracing systems to prevent the horizontal deformation in the wall trench and the swell on the bottom of the excavation as well as the settlement on the ground adjacent to the excavation.

There are several methods for stabilizing the trenches. Among these, one of the most widely used methods for deep excavation and stabilization of vertical trenches is the implementation of truss guarding structures that are abundant in the excavation of urban areas with the aim of minimizing the excavation effects onto adjacent structures. To carry out this type of guardian structure, firstly, at the location of the vertical member of trusses, which is located in the vicinity of walls of the trench, wells are drilled, whose depth is equal to the sum of the depth of excavation and an additional amount for the implementation of the underneath pile of the vertical member of trusses. In the next step, to create appropriate support for the vertical member of the truss, the end of the well by bars is reinforced and then the vertical truss profile is placed inside the well and after that concrete is placed at the end of the well. After hardening concrete, the lower end of the truss vertical member will act as a restrained member inside the concrete pile. After this stage, the soil is removed along a slope wall with a safe slope, and then the inclined member of the truss is executed, so that this member from one side to the vertical member, and on the other hand, is placed on the upper base plate of the foundation embedded in the bottom of the trench connected. The above operation is performed simultaneously for all guardian structures trusses along the slope wall simultaneously. In subsequent steps, the enclosed soil between the vertical and horizontal members of the trusses is removed step by step across the wall, and in each 
step, the horizontal and diagonal members of the truss are gradually installed to complete the truss guard structure. The steps of execution of the truss guardian structure are illustrated in Fig. 1.

Flennius was the first person that investigated the stability of the trenches [8], and then the stability of those in different methods, including the equilibrium method, the boundary element method [9], finite element method [10-14], and neural network methods [15] and other methods was investigated. The finite element method, called FEM, is one of the most common methods in modelling and solving problems in the field of engineering. Programs based on the finite element method such as Plaxis and Flac are able to solve different problems in geotechnical engineering.

In the present study, using the finite element method, the performance of the restrained wall by guardian truss structures using static and quasi-static approach was investigated.

The investigated items are as follow as:

(1) The geometric parameters of the trusses (distances between trusses).

(2) The geotechnical parameters of soil (modulus of elasticity, cohesion, friction angle of soil).

(3) The horizontal acceleration coefficient $\left(K_{h}\right)$.

(4) The construction stages.

The results of this research can help designers to find out the effects of the geotechnical parameters of the soil, the geometrical characteristics of the truss and effects of the horizontal acceleration coefficient $\left(K_{h}\right)$ and the construction stages on stability and deformations in the restrained wall by guardian truss structures using the

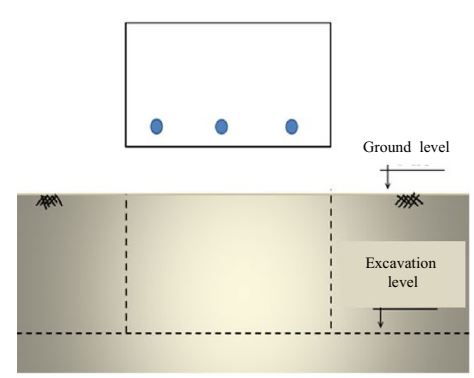

Step 1

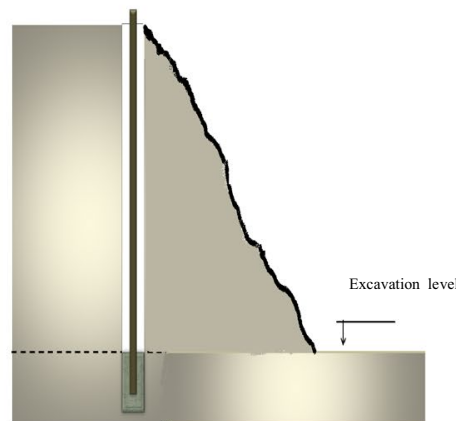

Step 4

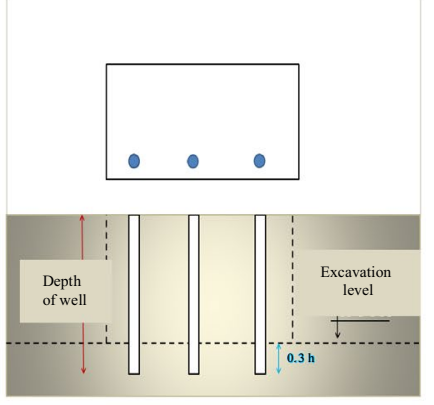

Step 2

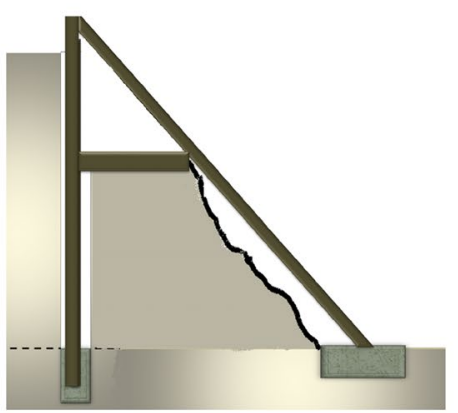

Step 5

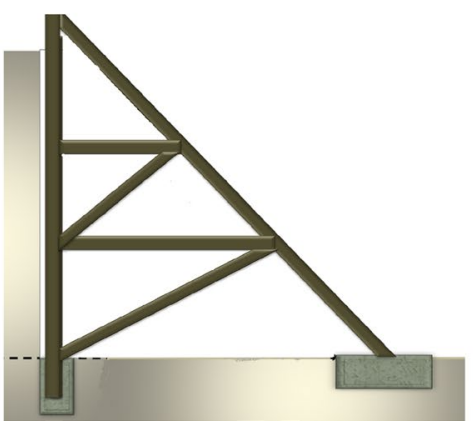

Step 7

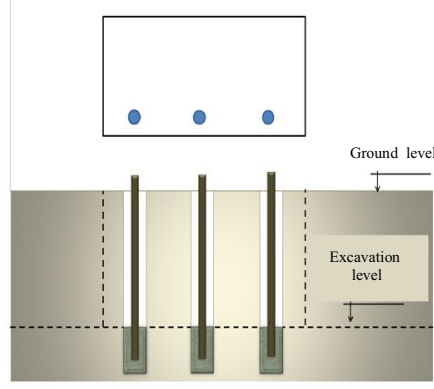

Step 3

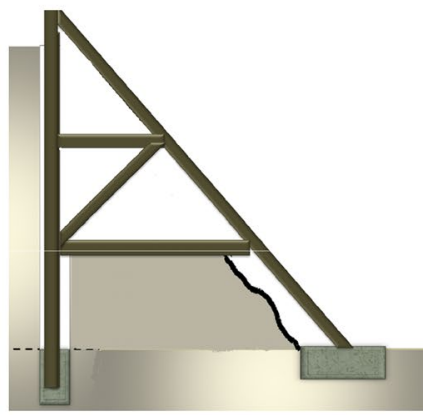

Step 6

Fig. 1 The steps of execution in the truss guardian structure and excavation procedure 
static and quasi-static approach. This issue can be the contribution of the present research for the geotechnical engineering community.

In this parametric study, the effect of the geometric parameters of the trusses, the effect of the geotechnical parameters of soil, the effect of the horizontal seismic acceleration coefficient $\left(K_{h}\right)$ and the construction stages on the maximum horizontal displacement, the maximum settling of the adjacent ground, the maximum swelling on the bottom of the trench and safety factor were investigated and the results have been discussed.

\section{Specifications of the studied project}

This research investigates the quasi-static behaviour of restrained vertical trench walls with guardian truss structures under the horizontal seismic acceleration of $0.1 \mathrm{~g}$ $\left(K_{h}=0.1\right)$ and comparison with static behaviour. The proposed parameters have been considered for modelling in accordance with Table 1, 2 and 3.

\section{Finite element modelling}

Problems that one of the dimensions is significantly larger than the other dimensions and they have the same geometry in depth and also they have similar loading in depth so that there is no deviation from the centre on

Table 1 Parameters of soil

\begin{tabular}{ll}
\hline Parameter & Value \\
\hline Unit weight $\gamma\left(\mathrm{kN} / \mathrm{m}^{3}\right)$ & 19 \\
Secant stiffness, $E_{50}{ }^{r e f}\left(\mathrm{kN} / \mathrm{m}^{2}\right)$ & $5.1 \times 10^{4}$ \\
Consolidated tangent module, $E_{\text {oed }}{ }^{r e f}\left(\mathrm{kN} / \mathrm{m}^{2}\right)$ & $5.1 \times 10^{4}$ \\
Loading and unloading stiffness, $E_{u r}{ }^{r}\left(\mathrm{kN} / \mathrm{m}^{2}\right)$ & $1.53 \times 10^{5}$ \\
Coefficient, $m$ & 0.5 \\
Cohesion, $c\left(\mathrm{kN} / \mathrm{m}^{2}\right)$ & 28.5 \\
Friction angle, $\phi(\mathrm{deg})$ & $28.5^{\circ}$ \\
Dilation Angle, $\psi(\mathrm{deg})$ & $0^{\circ}$ \\
Poisson's ratio for unloading/reloading, $v_{u r}$ & 0.3 \\
Horizontal seismic acceleration coefficient, $\left(K_{h}\right)$ & 0.1 \\
\hline
\end{tabular}

Table 3 Parameters of the foundation of the oblique elements in the trusses

\begin{tabular}{ll}
\hline Parameter & Value \\
\hline Axial stiffness of the foundation, $E A(\mathrm{kN} / \mathrm{m})$ & $1.05 \times 10^{9}$ \\
$\begin{array}{l}\text { Flexural stiffness of vertical elements of the trusses, EI } \\
\left(\mathrm{kN} . \mathrm{m}^{2} / \mathrm{m}\right)\end{array}$ & 2229.2 \\
Poisson's ratio, $v$ & 0.2 \\
\hline
\end{tabular}

the loading plate can examine as two-dimensional plane strain problems. One of the cases which are considered as two-dimensional planar unit deformation problem is the restrained wall trenches. Wall deflections and ground settlements are commonly anticipated by two methods. The first method is an interpolation from published empirical data sets. Researcher such as Peck [16] and Clough and O'Rourke [17] as well as Puller [18] have used this method for their research work. The second technique is analytical and numerical methods such as finite-element analyses that it was used by researchers such as Chang and Duncan [19], Burland and Hancock [20], Simpson et al. [21], Powrie and Batten [22]. Numerical methods are nowadays standard practice in the research community and geotechnical engineering profession.

In geotechnical engineering, two-dimensional analyses using the finite element method can find approximate results in areas of loading, bearing capacity, ground-structure interaction, consolidation, stress deformation, flow net and ground dynamics and etc.

In the present study, PLAXIS 2D finite element software for the analysis of soil deformation and stability has been used [23] that has been developed for the applications of geotechnical engineering.

The general geometry considered in this paper is illustrated in Fig. 2. The plane-strain state has been used to analyze the deformations. A continuum in the finite element method is divided into a number of quad or triangular elements. Each element consists of a number of nodes. In this research, the soil elements have been considered as triangular and 15 nodes. In the PLAXIS 2D finite element software, the stress-deformation behaviour of the material is modelled with nonlinear solution techniques and this software is consist of different mechanical behavior of soil.
Table 2 Parameters of vertical and oblique elements for the trusses

\begin{tabular}{ll}
\hline Parameter & Value \\
\hline Horizontal distance between trusses, $S_{h}(\mathrm{~m})$ & 3 \\
Axial stiffness of oblique elements of the trusses, $E A(\mathrm{kN})$ & $9.3 \times 10^{5}$ \\
Axial stiffness of vertical elements of the trusses, $E A(\mathrm{kN} / \mathrm{m})$ & $1.14 \times 10^{6}$ \\
Flexural stiffness of vertical elements of the trusses, $E l\left(\mathrm{kN} \cdot \mathrm{m}^{2} / \mathrm{m}\right)$ & 5229 \\
Poisson's ratio, $v$ & 0.2 \\
\hline
\end{tabular}




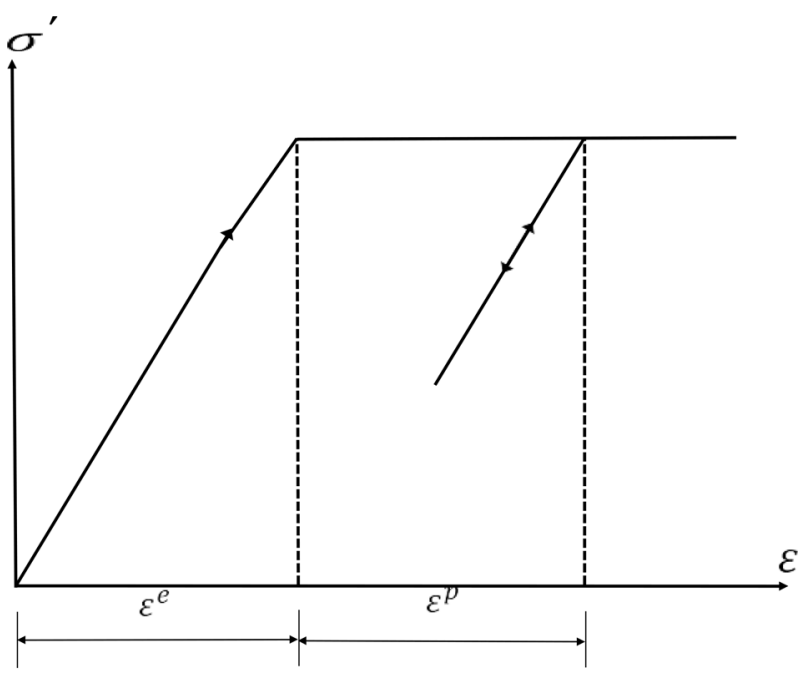

Fig. 2 The elastic perfectly-plastic model

Among these mechanical behavior of soils with various degrees of accuracy, the Mohr-Coulomb (MC) model is a well-known model for geotechnical analysis. The linear elastic perfectly-plastic Mohr-Coulomb is called the linear elastic perfectly-plastic model with the MohrCoulomb failure criterion. In other words, it is called the Mohr-Coulomb model. The MC model is including five parameters as follows:

(1) Cohesion $\left(c\left(k N / m^{2}\right)\right)$.

(2) Friction angle $\left(\phi\left(^{\circ}\right)\right)$.

(3) Young's modulus $\left(E\left(\mathrm{kN} / \mathrm{m}^{2}\right)\right)$.

(4) Poisson's ratio $(v)$.

(5) Dilatancy angle $\left(\psi\left(^{\circ}\right)\right)$.

The MC model is a combination of Hooke's law and the generalized form of Coulomb's failure criterion. Strains are broken down into an elastic part and a plastic part that it is the basic principle of the Mohr-Coulomb model as shown in Fig. 3.

The stiffness behavior below the failure contour is assumed to be linear elastic that it was defined by a constant modulus of elasticity and Poisson's ratio. Hence, the model has a limited capability to accurately model deformation behavior before failure [24]. Therefore, a more complete behavioral model for soil should be used.

In this study, the Hardening soil behavioral model (HS) has been used for material model in soil. The hardening soil model is an advanced model for simulating the behavior of different types of soil. A main feature of the hardening soil model is the stress dependency of soil stiffness. As shown in Fig. 4, the relationship between the deviatoric stress $(q)$ and the vertical strain $\left(\varepsilon_{1}\right)$ can be estimated by a hyperbolic shape. The hardening soil

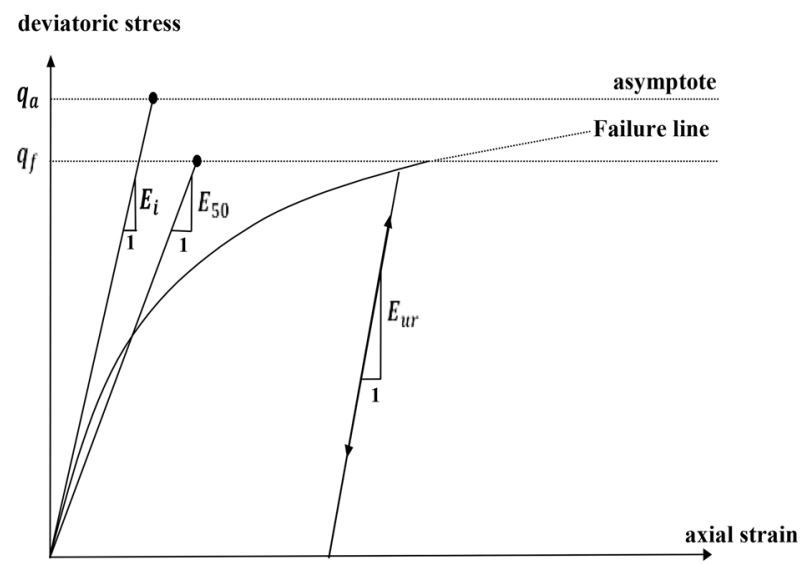

Fig. 3 The hyperbolic shape, the relationship between the vertical strain $\left(\varepsilon_{1}\right)$ and the deviatoric stress $(q)$

model (HS) has two advantage over the Mohr-Coulomb model (MC) as follows:

1. The use of a hyperbolic stress-strain curve instead of a bilinear curve (the elastic perfectly-plastic model as shown in Fig. 3).

2. The control of stress level dependency.

3. In the Mohr-Coulomb (MC) model, Young's modulus is considered constant whereas, in the hardening soil model (HS) for real soils, Young's modulus depends on the stress level.

4. The hardening soil model by using the initial load value of the reference is considered to be $100 \mathrm{kPa}$ by default $\left(p^{\text {ref }}\right)$ and automatically changes the stressdependent stiffness modulus.

The HS model including input of seven parameters that are entered into the Plaxis program:

1. Mohr-Coulomb strength parameters such as cohesion $(c)$, internal friction angle $(\phi)$, dilatancy Angle $(\psi)$. Among these parameters, the dilatancy Angle $(\psi)$ in cohesionless materials depends on the friction angle of the soil and relative density, which is for soil aggregates with an internal friction angle greater than $30^{\circ}$ is estimated about $\psi=\phi-30^{\circ}$ [25].

2. Other parameters such as horizontal and vertical permeability coefficients $\left(k_{v}\right.$ and $\left.k_{h}\right)$, dry and natural unit volume weights of the ground ( $\gamma_{\text {sat }}$ and $\left.\gamma_{\text {unsat }}\right)$.

3. Reference stiffness parameters at reference stress level $p^{\text {ref }}$ (default $p^{\text {ref }}=100 \mathrm{kPa}$ in this study) [26].

- $E_{50}{ }^{\text {ref }}$ for triaxial compression, secant stiffness in the standard drained triaxial test $\left(\mathrm{kN} / \mathrm{m}^{2}\right)$. 
Fig. 4 The general geometry of numerical models constructed in the present study

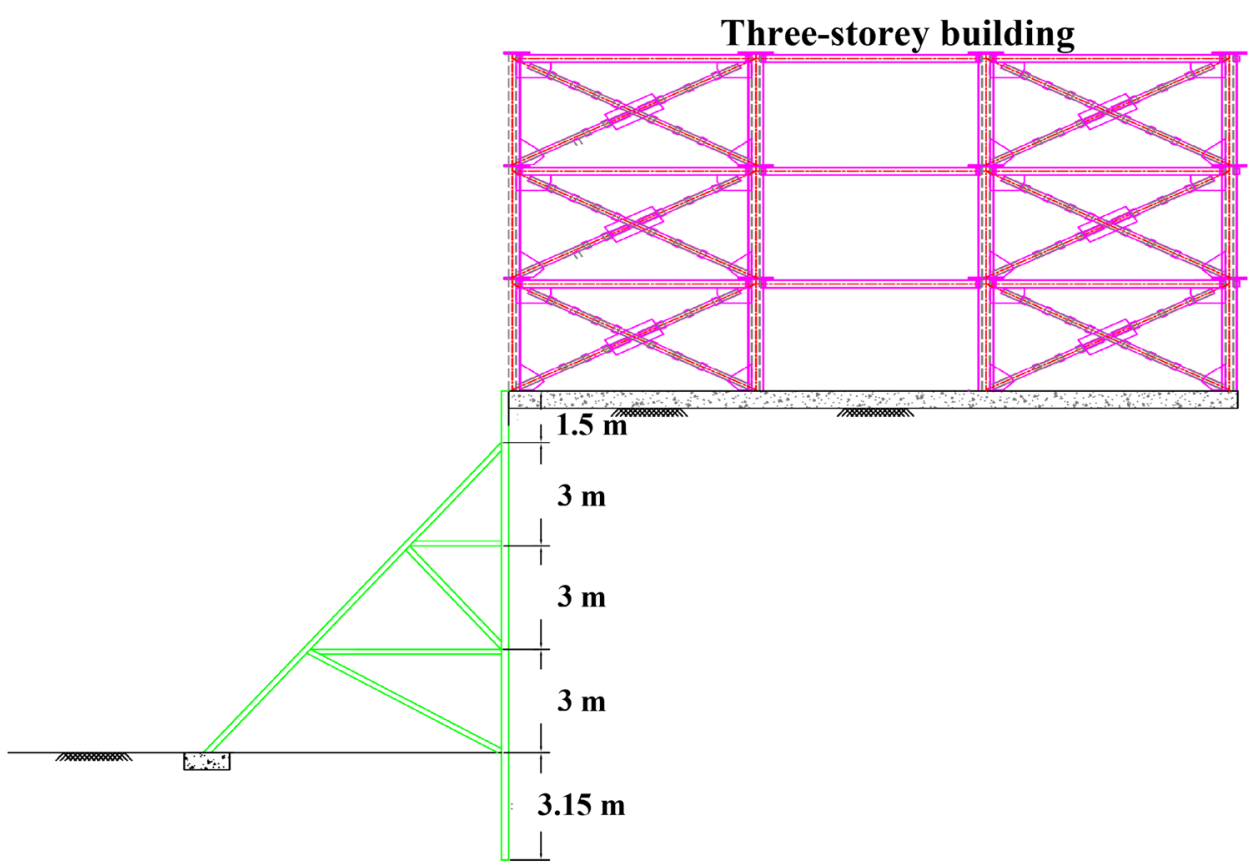

- $\mathrm{E}_{\mathrm{ur}}{ }^{\text {ref }}$ for triaxial unloading/reloading, tangent stiffness for primary oedometer loading $\left(\mathrm{kN} / \mathrm{m}^{2}\right)$.

- $\mathrm{E}_{\text {oed }}{ }^{\text {ref }}$ for oedometer loading; unloading/ reloading stiffness at engineering strains $\left(\mathrm{kN} / \mathrm{m}^{2}\right)$.

Proposed the following relations between parameters of $E_{50}{ }^{\text {ref }}$ and $E_{\mathrm{ur}}{ }^{\text {ref }}$ and $E_{\text {oed }}{ }^{\text {ref }}$ can be obtained as follows:

$E_{50}^{r e f}=E_{\text {oed }}^{r e f}=0.33 E_{u r}^{r e f}$

4. A power for the stress-level dependency of stiffness $m$.

5. A parameter called the failure ratio $R_{f}$, which is the ratio of $q_{f}=q_{a}$ (Fig. 4).

6. Poisson's ratio for unloading/reloading $\left(v_{u r}\right)$.

7. $\mathrm{K}_{\mathrm{o}}$-value for normal consolidation $\left(K_{o}{ }^{n c}\right)$.

The parameters for the HS model are listed in Table 1.

In order to take into account the position of the contact surface between different materials, the coefficient of shear strength reduction $\left(R_{\text {inter }}\right)$ is used which is equal to the ratio of the coefficient of friction in the contact surface of two types of materials (concrete and soil) to each other. The value of this coefficient for the contact surface between the soil and the wall 0.65 has been considered [27].

According to the recommendation of Lees [28], the minimum horizontal distance between the vertical edges of the trench should be 4 times its height so that the effects of the boundaries of the model on the results of the analysis was minimized. This recommendation is used for the distance between the vertical and lower bounds of the numerical model (Fig. 5). Investigating the stress contours and as well as the displacement contours obtained from numerical modeling indicates that this distance is sufficient. Also, The lower boundary of the model has been fixed against horizontal and vertical movements and lateral boundaries have been fixed against horizontal movements.

The finite element mesh in the models made for this study has been shown in Fig. 5. Several numerical modelling were performed with different mesh dimensions and each time with smaller mesh dimensions until the changes in displacement became too small by modifying the mesh dimensions. Triangular elements were considered smaller near the wall trench and the floor of the excavation.

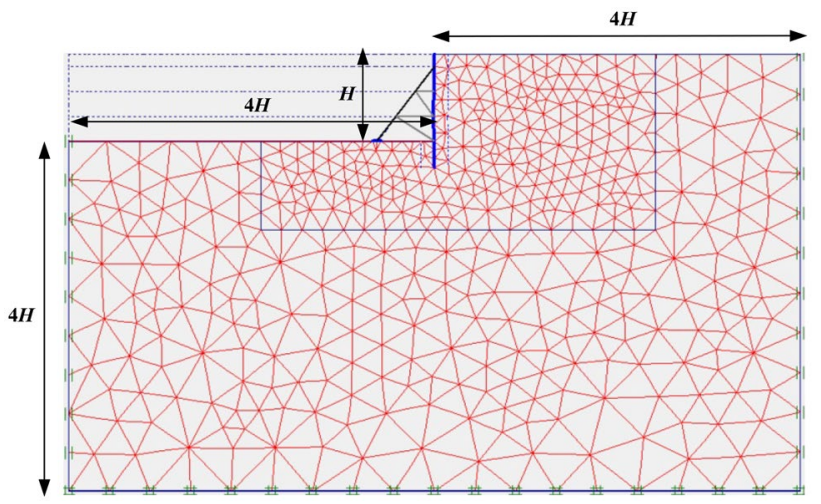

Fig. 5 The finite element mesh in the present study 
For real modelling of soil deformation, first, the overhead caused by the three-storey building which is 3 tons per square metre $\left(30 \mathrm{kN} / \mathrm{m}^{2}\right)$ is considered. In the next step, the initial displacement is considered zero, and then the stages of modelling of the excavation and installation of truss elements in 4 stages (in the first stage $1.5 \mathrm{~m}$ and in the next three steps each of $3 \mathrm{~m}$ that overall height of wall trench will be $H=10 \mathrm{~m}$ ), fully are modelled in the finite element software. In the next step, the quasi-static analysis has been considered in the model with the horizontal acceleration coefficient $K_{h}=0.1$ and in the final step of the analysis, the stability coefficient (safety factor) has been considered. The flowchart of the finite element modelling for the clarity of analyses performed in this research has been illustrated in Fig. 6 .

The design of the trussed guard structure was done using the diagrams of the principles of excavation bases and guard structures [29] and taking into account the parameters in Table 1, 2, 3.

\section{Verification of the numerical model}

Figure 7 shows the horizontal displacement vectors in finite element analysis. As can be seent he direction of horizontal displacements at the top and bottom of the wall is different so that the displacement at the top of the wall is passive and towards the inside of the wall, and vice versa, at the bottom of the wall, the horizontal displacements are active. As can be seen from Fig. 7, the most horizontal displacement occurs at the highest point of the wall.

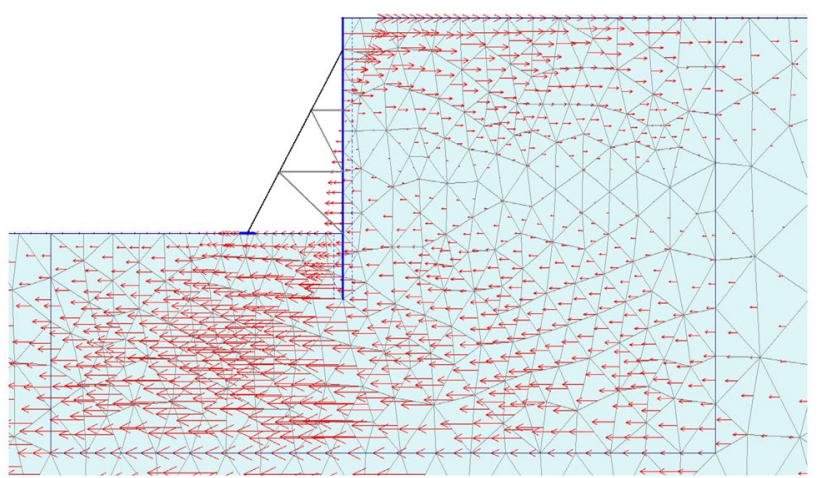

Fig. 7 The horizontal displacement vectors in the finite element analysis

For evaluating the influences of different factors on seismic performances of the deep excavation, Prior to parametric studies the numerical model has to be verified and checked for reliable estimation and results. To assess the accuracy and validity of the model the field data from surveying of a real deep excavation in the city of Tehran were used. The data consisted of horizontal displacements of a trench measured by surveying method from top to the bottom.

To monitor the horizontal displacement of the trench by the surveying team, at the first step, points on the trench are considered. Then tools called reflectors are installed in these points, and in the next step, the surveying team, using surveying cameras called Total station, obtain the three-dimensional coordinates of the points where the
Fig. 6 The flowchart of the finite element modelling

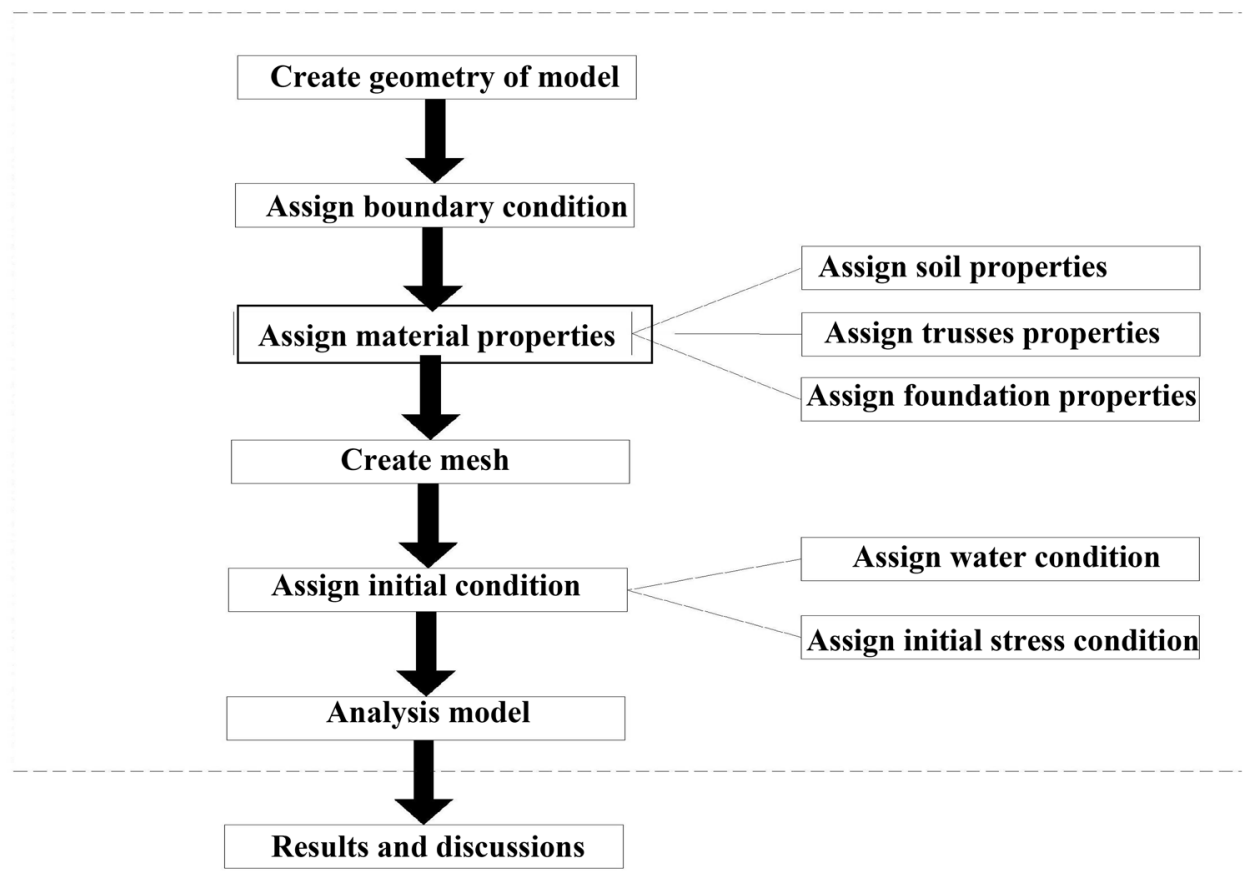




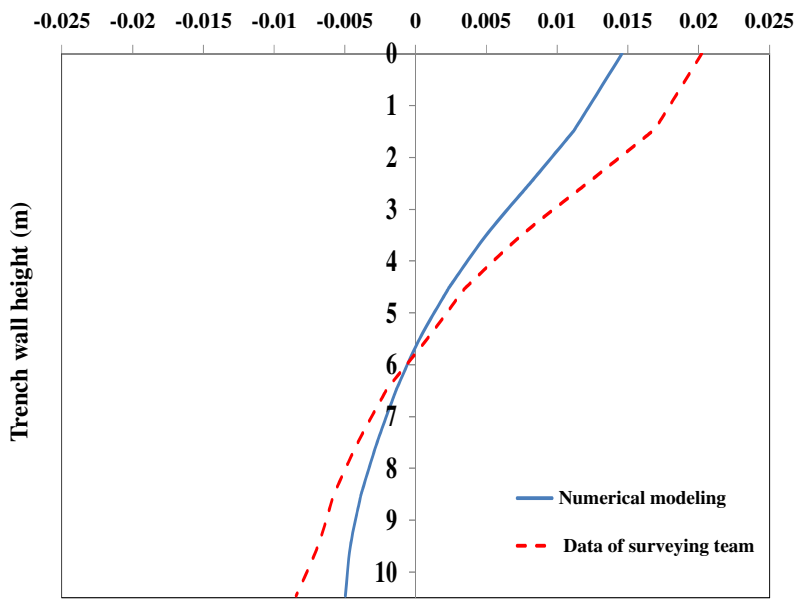

Horizontal displacement of the trench wall $(\mathrm{m})$

Fig. 8 Comparison between the numerical modeling and field data

reflector is installed on the wall, and then they enter coordinates of the points into the computer. In the next step, using the obtained coordinates and comparing with the initial coordinates of the placement of the reflectors, the horizontal displacement value in the trench can be obtained then the diagram (trench wall height-horizontal displacement) can be obtained according to Fig. 8. The results of numerical analyses for the same trench were obtained and compared with the field data. In Fig. 8 the horizontal displacements of the above trench estimated from numerical model and measured by surveying technic are illustrated in the same coordinates. As can be seen in Fig. 8, in spite of some differences between the results from the two methods, the general trend and variations of the horizontal displacement from top to bottom of the trench are in good agreement and the numerical modeling shows relatively reliable and acceptable results for parametric studies in the present research.

\section{Sensitivity analysis of the parameters}

In the present study using static and quasi-static analysis, effects of the geometric parameters of trusses (distances between trusses), geotechnical parameters of soil $(E, C, \phi)$ and the horizontal seismic acceleration coefficient $\left(K_{h}\right)$ and construction stages on the maximum horizontal displacement, the maximum vertical displacement (the maximum settling of the adjacent ground, the maximum swelling on the bottom of the trench) and the safety factor of the vertical trench wall (FOS) have been investigated and the results have been discussed. The research method is that by changing the parameters introduced in Sect. 2 and maintaining other parameters, the effect of these parameters on the maximum horizontal and vertical displacement and the safety factor (FOS) are investigated.

\subsection{Effect of the horizontal distance of the trusses on the stability and deformations}

It can be seen from Fig. 9, by decreasing the horizontal distance of the trusses from one another $\left(S_{h}=2,3,4,5 \mathrm{~m}\right)$, the maximum horizontal displacement of the wall reduced but this is not a big increase, so can almost assume it fixed, as well as the maximum horizontal displacement of the vertical trench wall from the quasi-static analysis is much more than to the maximum horizontal displacement from static analysis.

As shown in Fig. 10, in both static and quasi-static analyzes, the safety factor (FOS) reduced by increasing the horizontal distance of the trusses from one another, also the safety factor from the quasi-static analysis is less than static analysis.

Figure 11 shows, in both static and quasi-static analyzes, by increasing the horizontal distance of the trusses from one another, the maximum settling of the adjacent ground will increase. Also, the maximum settling of the adjacent ground from the quasi-static analysis is more than static analysis.

According to Fig. 12, it can be found that with the increase of the horizontal distance of the trusses, the maximum swelling on the bottom of the trench will increase. Also, the maximum swelling on the bottom of the trench from the quasi-static analysis is more than static analysis.

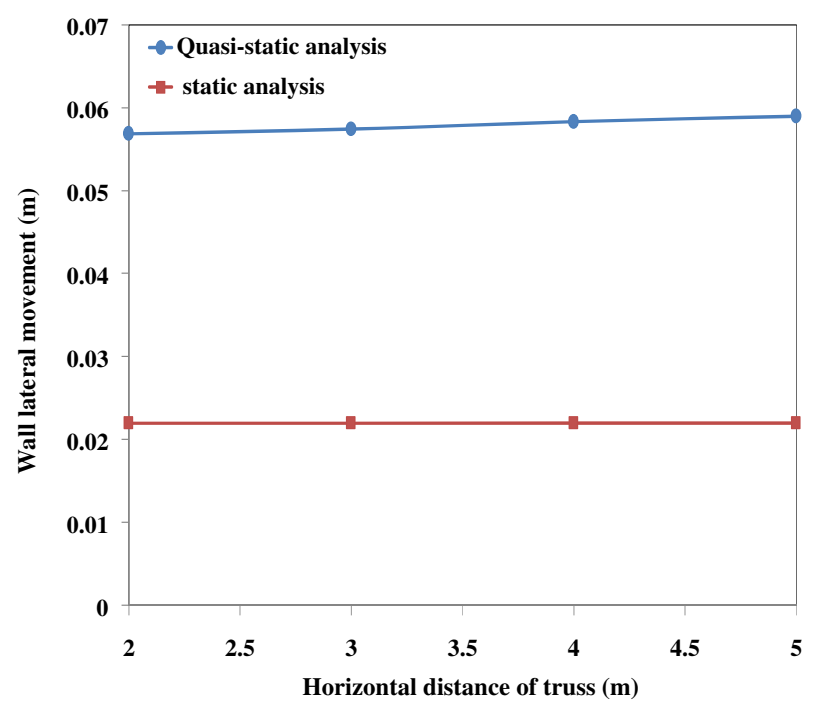

Fig. 9 Effect of change in the horizontal displacement of the truss on the wall lateral movement 


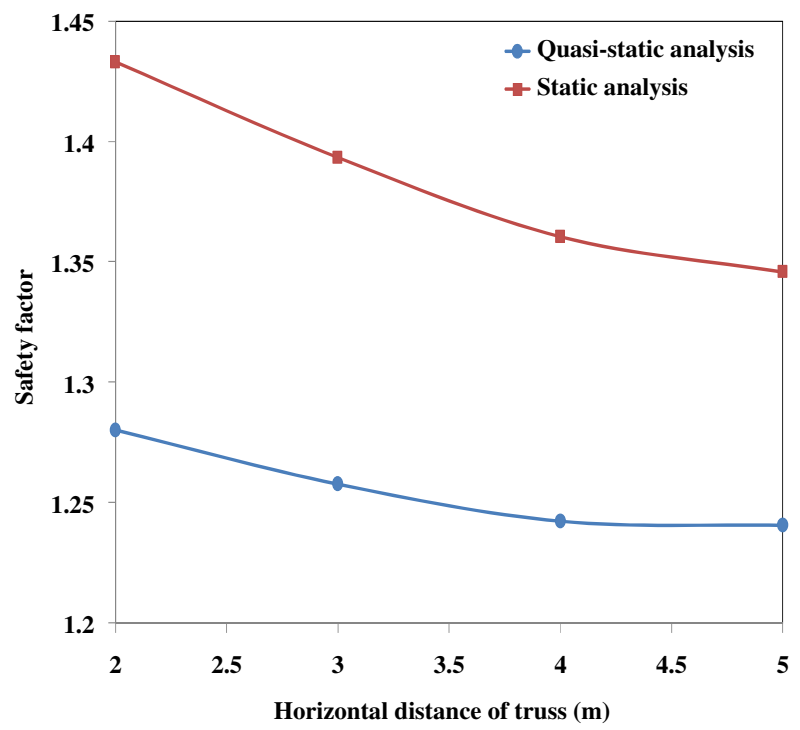

Fig. 10 Effect of change in the horizontal displacement of the truss on the safety factor

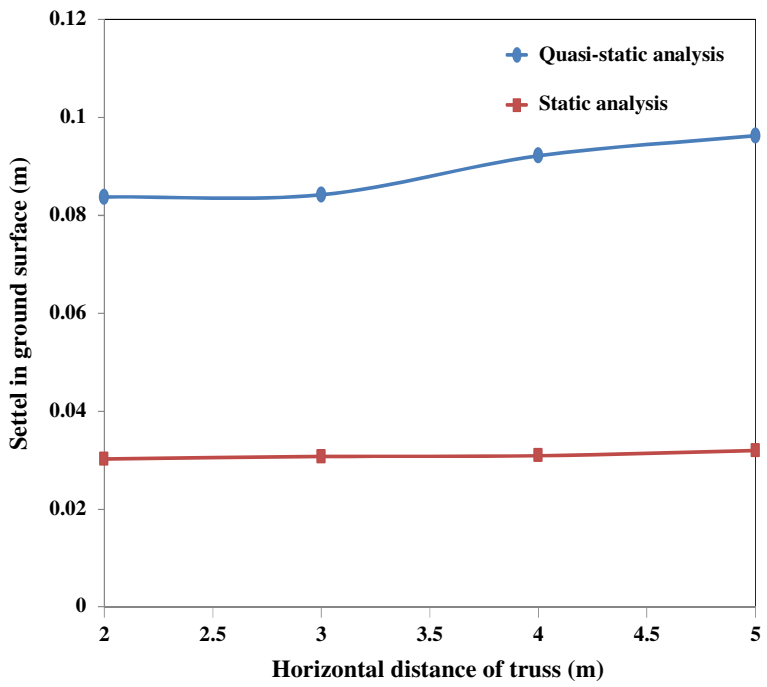

Fig. 11 Effect of change in the horizontal displacement of the truss on the settle in the ground surface

\subsection{Effect of soil geotechnical parameters on the stability and deformations}

Figures 13 to 16 shows the effect of geotechnical parameters of soil on the maximum horizontal displacement of the trench, the maximum ground surface settlement, the maximum swelling of the on the bottom of the trench and the safety factor.

It can be seen Fig. 13, in both static and quasi-static analyzes, by increasing the cohesion of soil $(c=20,25,28.5$, $\left.30,35\left(\mathrm{kN} / \mathrm{m}^{2}\right)\right)$ the maximum horizontal displacement of the wall reduced, as well as the maximum horizontal

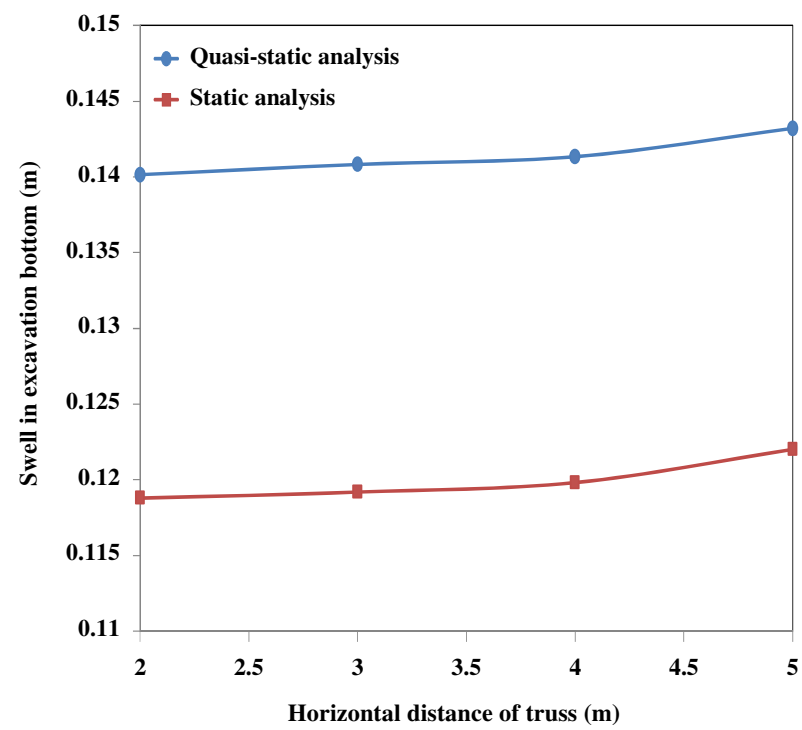

Fig. 12 Effect of change in the horizontal displacement of the truss on the swell in the excavation bottom

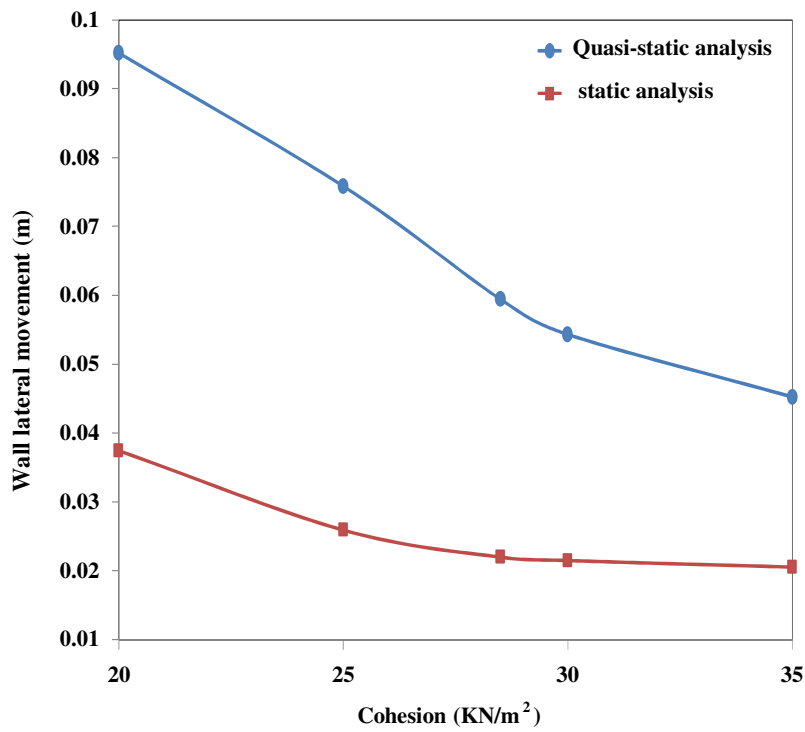

Fig. 13 Effect of change in the cohesion of soil on the wall lateral movement

displacement of the vertical trench wall from the quasistatic analysis is much more than to the maximum horizontal displacement from static analysis.

As shown in Fig. 14, in both static and quasi-static analyzes, by increasing the cohesion of soil, the safety factor (FOS) of the wall increase, as well as the safety factor of the vertical trench wall from the static analysis is much more than to the quasi-static analysis.

It can be seen from Fig. 15, by increasing the cohesion of soil, the maximum settling of the adjacent ground of the wall decrease, also the maximum settling of the adjacent 


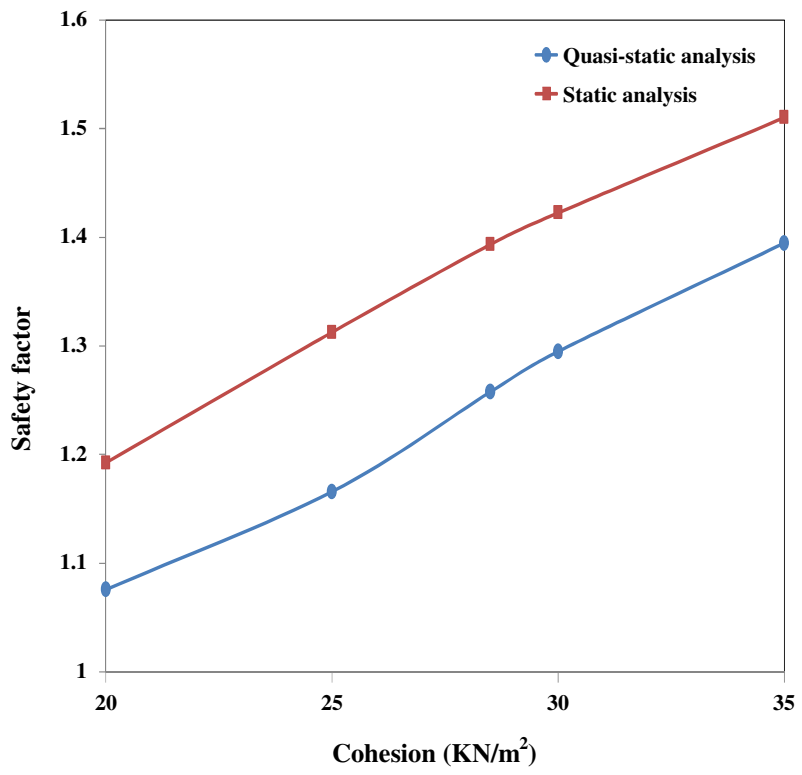

Fig. 14 Effect of change in the cohesion of soil on the safety factor

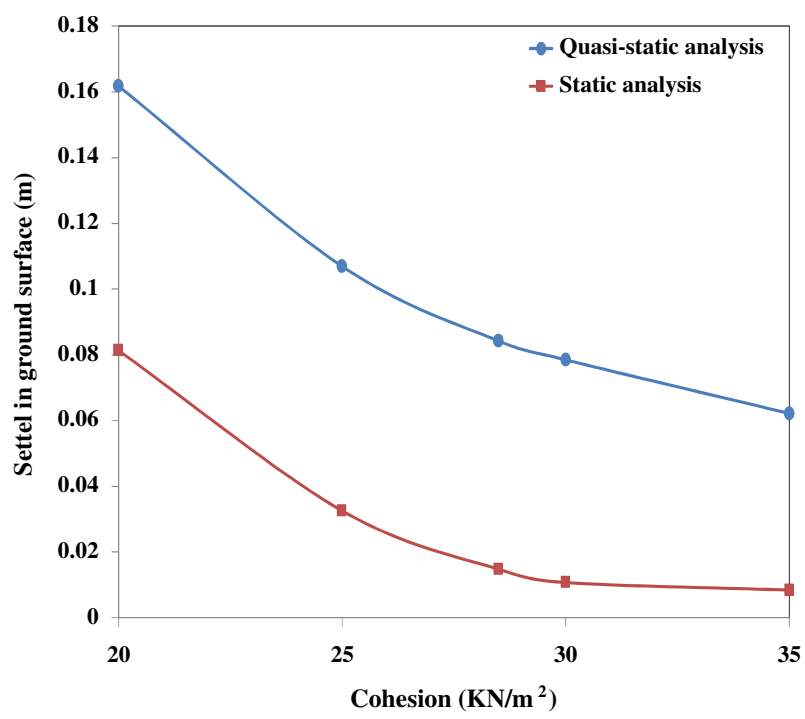

Fig. 15 Effect of change in the cohesion of soil on the settle in the ground surface

ground of the wall from the quasi-static analysis is much more than the maximum settling of the adjacent ground from static analysis.

According to Fig. 16, it can be found by increasing the cohesion of soil, the maximum swelling on the bottom of the trench will decrease. Also, the maximum swelling on the bottom of the trench from the quasi-static analysis is more than static analysis.

Figure 17 clearly show, in both static and quasi-static analyzes, by increasing the friction angle $\left(\phi=20^{\circ}, 25^{\circ}\right.$,

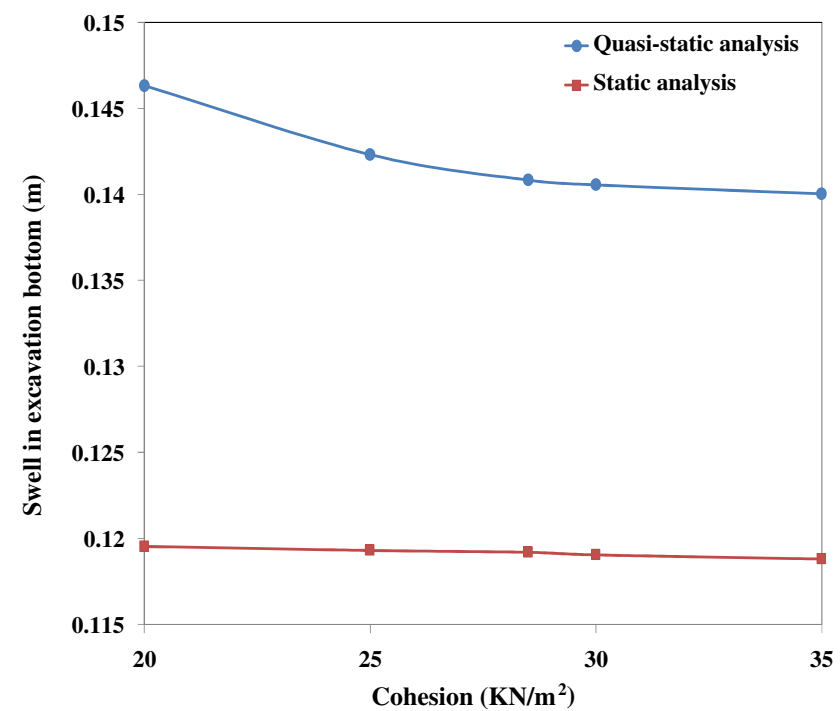

Fig. 16 Effect of change in the cohesion of soil on the swell in the excavation bottom

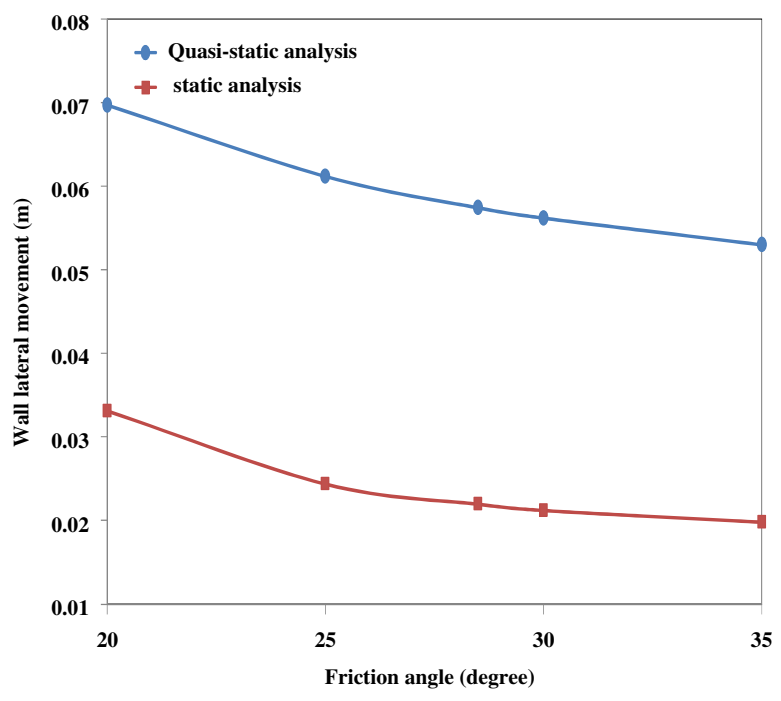

Fig. 17 Effect of change in the angle friction of soil on the wall lateral movement

$28.5^{\circ}, 30^{\circ}, 35^{\circ}$ ) of soil the maximum horizontal displacement of the wall reduced, as well as the maximum horizontal displacement of the vertical trench wall from the quasi-static analysis is much more than to the maximum horizontal displacement from static analysis.

As shown in Fig. 18, in both static and quasi-static analyzes, by increasing the friction angle of soil, the safety factor of the wall increase, as well as the safety factor (FOS) of the vertical trench wall from the static analysis is much more than to the safety factor from the quasistatic analysis. 


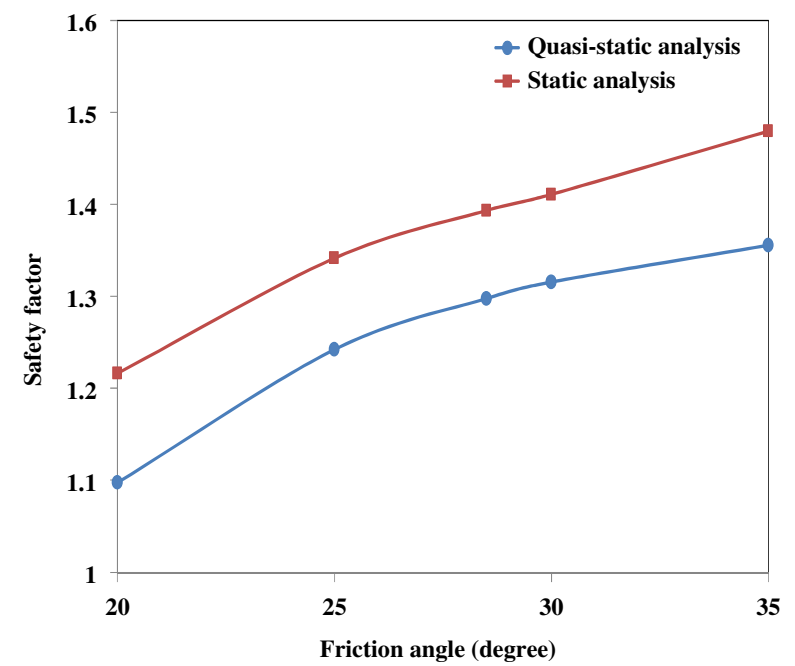

Fig. 18 Effect of change in the angle friction of soil on the safety factor

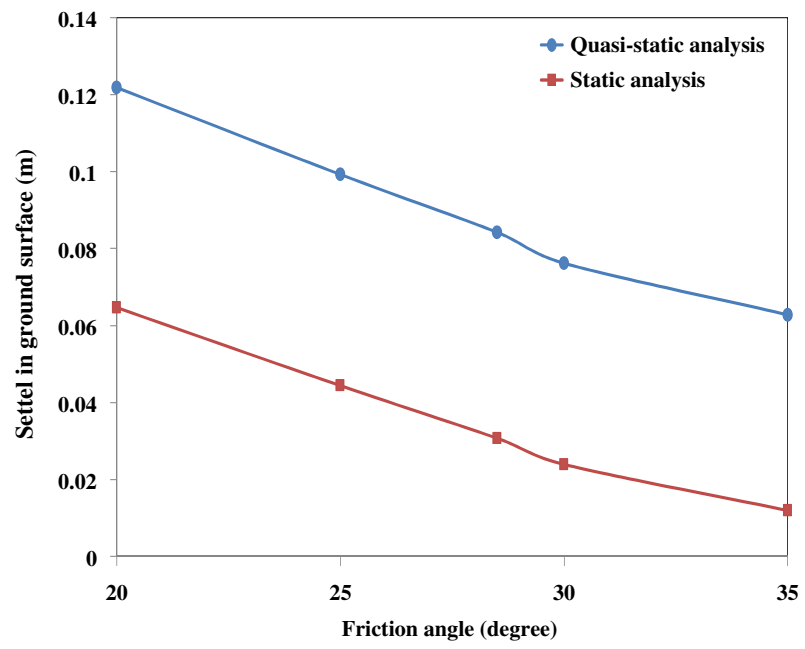

Fig. 19 Effect of change in the angle friction of soil on the settle in the ground surface

It can be seen from Fig. 19, by increasing the friction angle of soil the maximum settling of the adjacent ground of the wall decrease, also the maximum settling of the adjacent ground of the wall from the quasi-static analysis is much more than the maximum settling of the adjacent ground from static analysis.

According to Fig. 20, it can be found that with the increase of the friction angle of soil, the maximum swelling on the bottom of the trench will decrease. Also, the maximum swelling on the bottom of the trench from the quasi-static analysis is more than static analysis.

Figure 21 shows that in both static and quasi-static analyzes, by increasing the modulus of elasticity of soil $\left(E_{50}{ }^{\text {ref }}=2 \times 10^{4}, 4 \times 10^{4}, 5.1 \times 10^{4}, 6 \times 10^{4}, 8 \times 10^{4}\left(\mathrm{kN} / \mathrm{m}^{2}\right)\right)$

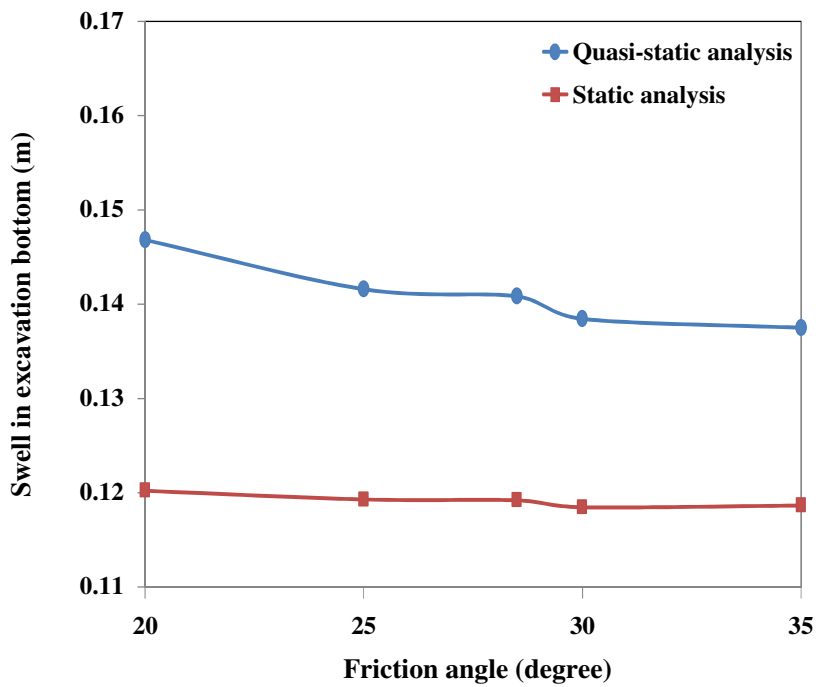

Fig. 20 Effect of change in the angle friction of soil on the swell in the excavation bottom

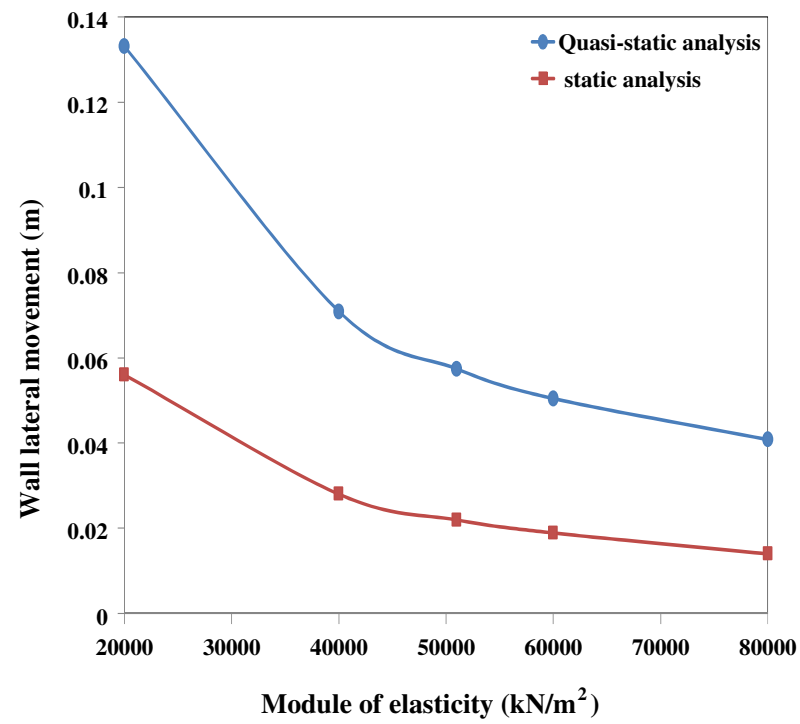

Fig. 21 Effect of change in the modulus of elasticity on the wall lateral movement

and considering $E_{50}{ }^{\text {ref }}=E_{\text {oed }}{ }^{\text {ref }}=0.33 E_{\text {ur }}{ }^{\text {ref }}$ (Eq. 5), the maximum horizontal displacement of the wall reduced, as well as the maximum horizontal displacement of the vertical trench wall from the quasi-static analysis is much more than to the maximum horizontal displacement from static analysis.

As shown in Fig. 22, in both static and quasi-static analyzes, by increasing the modulus of elasticity of soil the safety factor of the wall increase, as well as the safety factor (FOS) of the vertical trench wall from the static analysis is much more than to the horizontal displacement from the quasi-static analysis. 


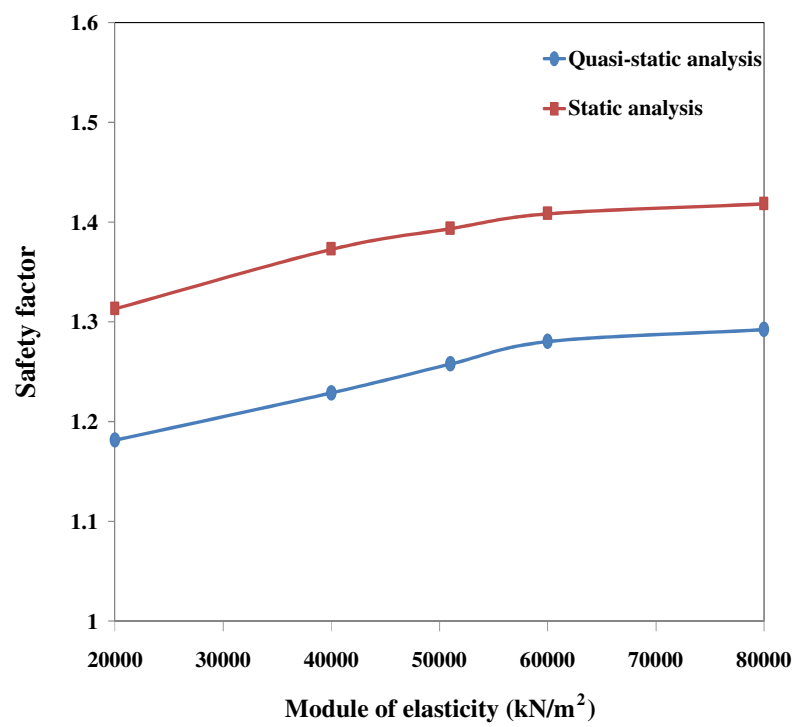

Fig. 22 Effect of change in the modulus of elasticity on the safety factor

It can be seen from Fig. 23, by increasing the modulus of elasticity of soil the maximum settling of the adjacent ground of the wall reduced, also the maximum settling of the adjacent ground of the wall from the quasi-static analysis is much more than the maximum settling of the adjacent ground from static analysis.

According to Fig. 24, it can be found, by increasing the modulus of elasticity of soil, the maximum swelling on the bottom of the trench will decrease. Also, the maximum swelling on the bottom of the trench from the quasi-static analysis is more than static analysis.

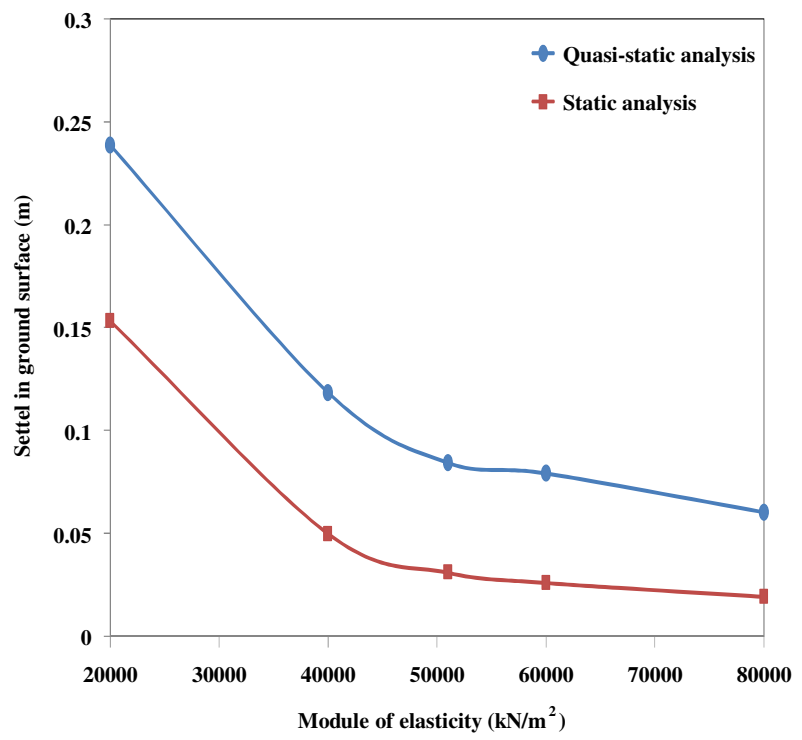

Fig. 23 Effect of change in the modulus of elasticity on the settle in the ground surface

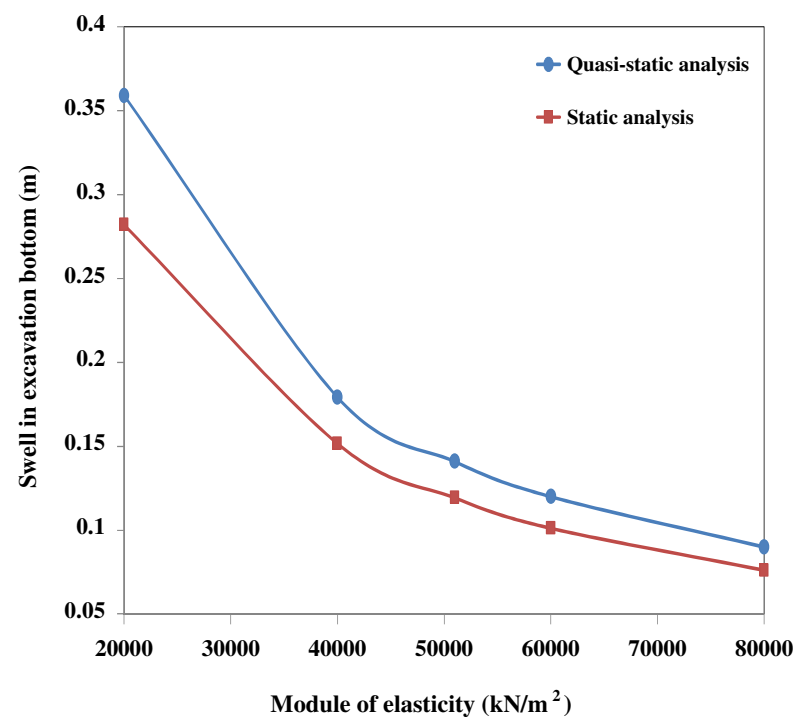

Fig. 24 Effect of change in the modulus of elasticity on the swell in the excavation bottom

\subsection{Effect of the horizontal seismic acceleration coefficient $\left(K_{h}\right)$ on the stability and deformations}

The quasi-static method is used for stability and determination in the circular and non-circular linear sliding surfaces of slopes. An earthquake can put the slipping mass in the failure wedge under the influence of both vertical and horizontal quasi-static forces, but in most earthquakes, the maximum vertical acceleration is less than the maximum horizontal acceleration. Therefore $K_{v}<K_{h}$ and as a result of $F_{v}<F_{h}$ and the vertical quasi-static force will have less effect on the stability and usually will be neglected. Therefore in the seismic analysis of the trenches, only $F_{h}$ as the force on slipping mass will be considered. By increasing the horizontal seismic acceleration coefficient $\left(K_{h}=0,0.1\right.$, $0.2,0.3,0.4$ ), the horizontal force generated by the earthquake in the center of the failure wedge increase, as a result of, as shown in Figs. 25, 26, 27, 28, the maximum horizontal displacement of the wall, the maximum settling of the adjacent ground of the wall, the maximum swelling on the bottom of the trench increase and the safety factor will decrease.

\subsection{Effect of construction stages on the stability and deformations}

The steps of execution of the truss guardian structure have been illustrated in Fig. 1. Soil stability is endangered when excavating soil. Therefore in Fig. 1, from step 4 to step 7 (in the four step), soil stability and deformations should be considered. 


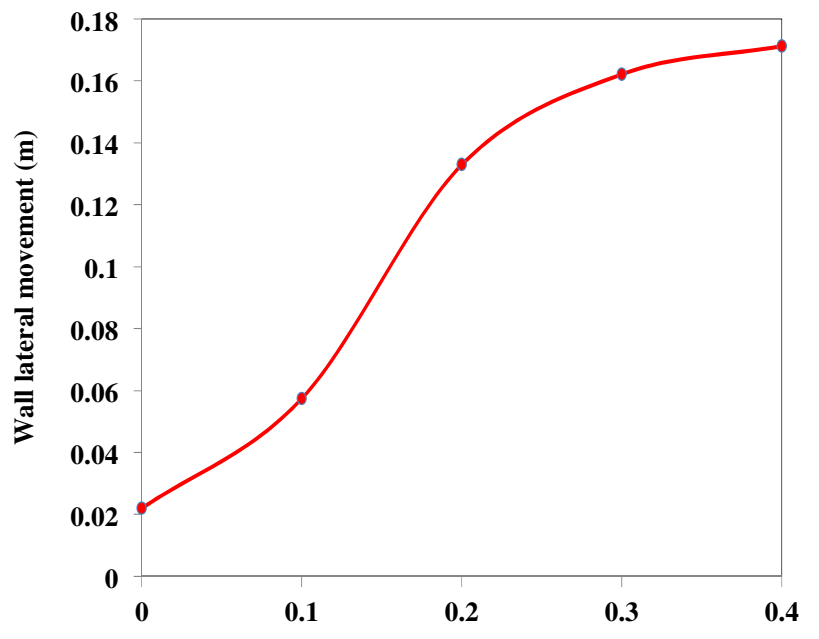

Horizontal seismic acceleration coefficient

Fig. 25 Effect of change in the horizontal seismic acceleration coefficient on the wall lateral movement

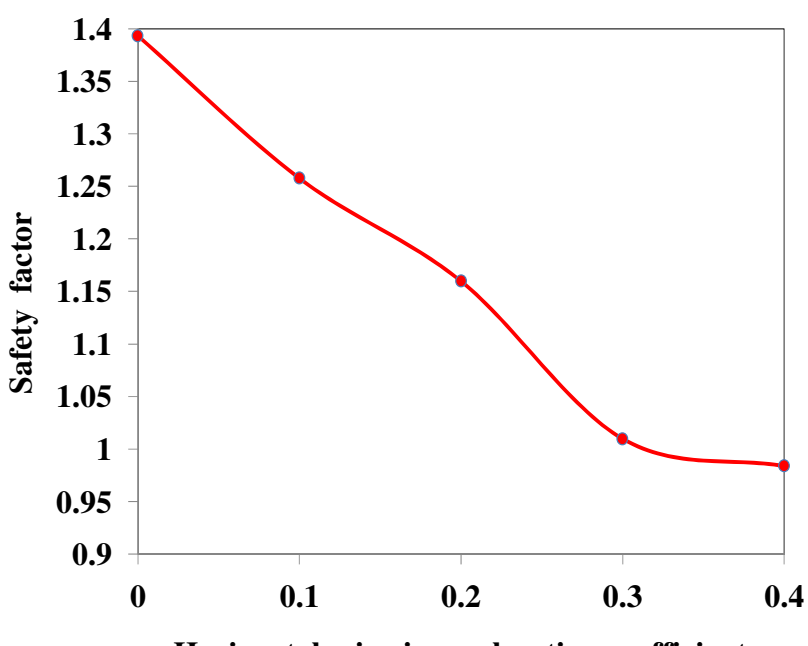

Horizontal seismic acceleration coefficient

Fig. 26 Effect of change in the horizontal seismic acceleration coefficient on the safety factor

In this section, using static and quasi-static seismic analysis, the effect of construction stages of the excavation restrained by truss structures (in the four step) on the maximum horizontal displacement, the maximum settling of the adjacent ground, the maximum swelling on the bottom of the trench and safety factor investigated.

Figure 29 shows the trend in the variation of the horizontal displacement of the wall with construction stages of the excavation restrained by truss structures. From Fig. 29, it is evident that in both static and quasistatic analyzes, as the construction stages progress, the maximum horizontal displacement of the wall increase,

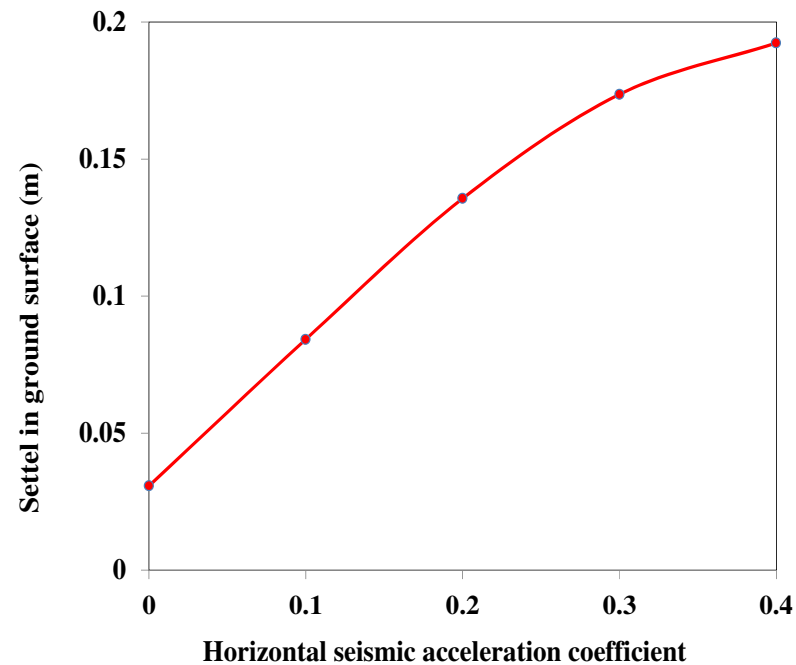

Fig. 27 Effect of change in the horizontal seismic acceleration coefficient on the settle in the ground surface

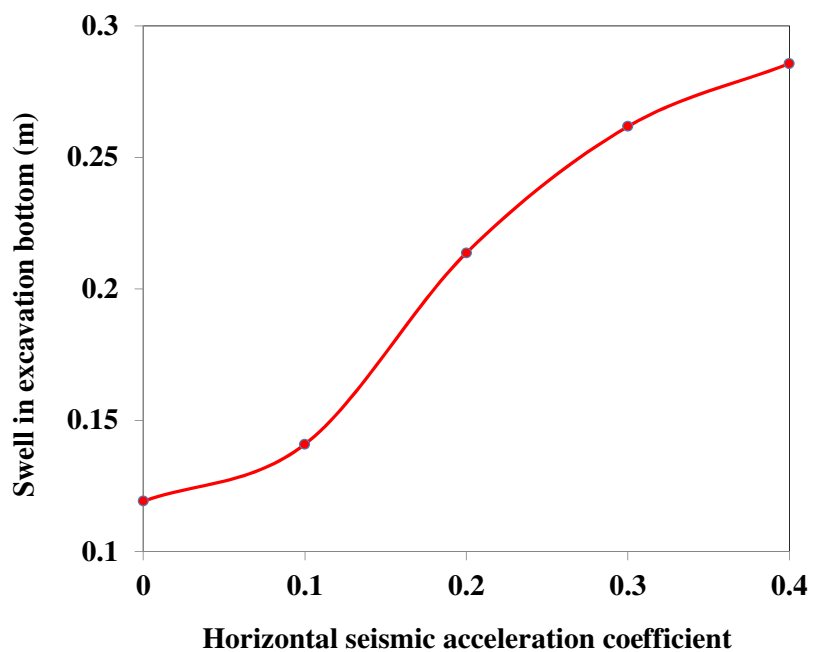

Fig. 28 Effect of change in the horizontal seismic acceleration coefficient on the swell in the excavation bottom

as well as the maximum horizontal displacement of the wall from the quasi-static analysis is much more than to the maximum horizontal displacement from the static analysis.

As shown in Fig. 30, in both static and quasi-static analyzes, as the construction stages progress, the safety factor of the wall decrease. The safety factor (FOS) of the vertical trench wall from the static analysis is much more than to horizontal displacement from the quasi-static analysis.

It can be seen from Fig. 31, as the construction stages progress, the maximum settling of the adjacent ground of the wall increase, also the maximum settling of the adjacent ground of the wall from the quasi-static analysis is 


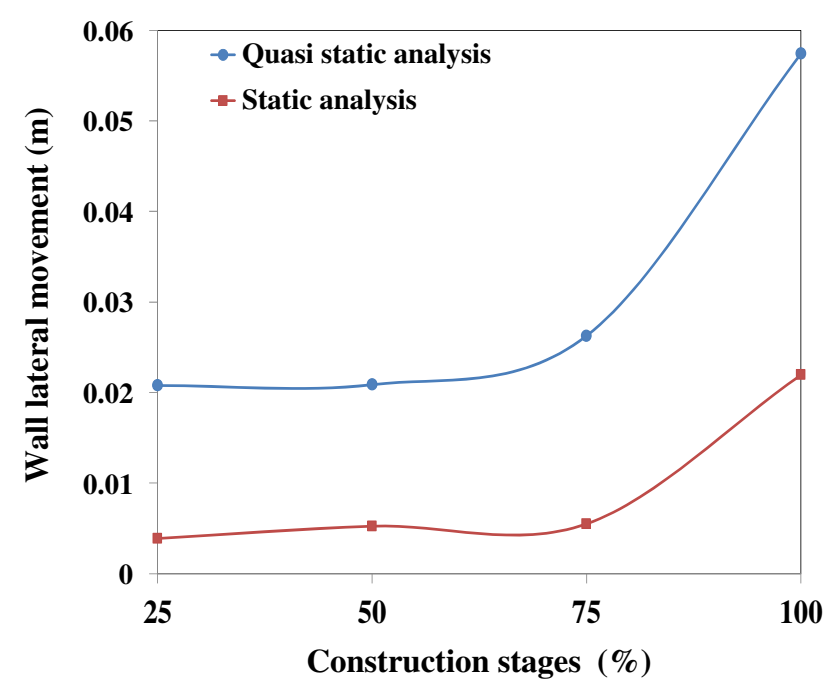

Fig. 29 Effect of change in construction stages on the wall lateral movement

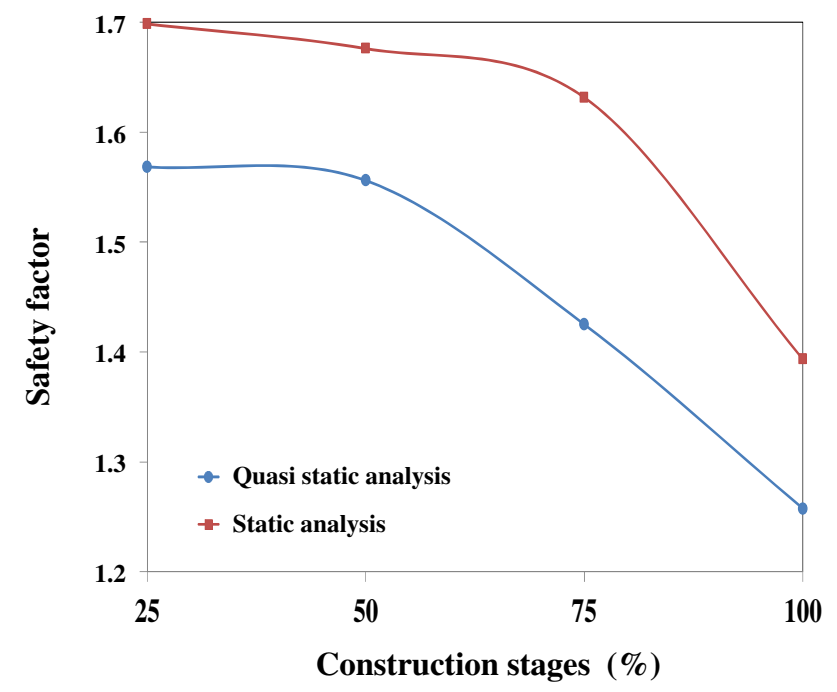

Fig. 30 Effect of change in construction stages on the safety factor

much more than to the maximum settling of the adjacent ground from static analysis.

According to Figs. 32 it can be found, as the construction stages progress, the maximum swelling on the bottom of the trench will increase. Also, the maximum swelling on the bottom of the trench from the quasi-static analysis is more than static analysis.

\section{Overall discussion}

Nowadays, the deformation and stability of the excavations are performed in different ways. The stability of the excavations with the truss guardian structure is

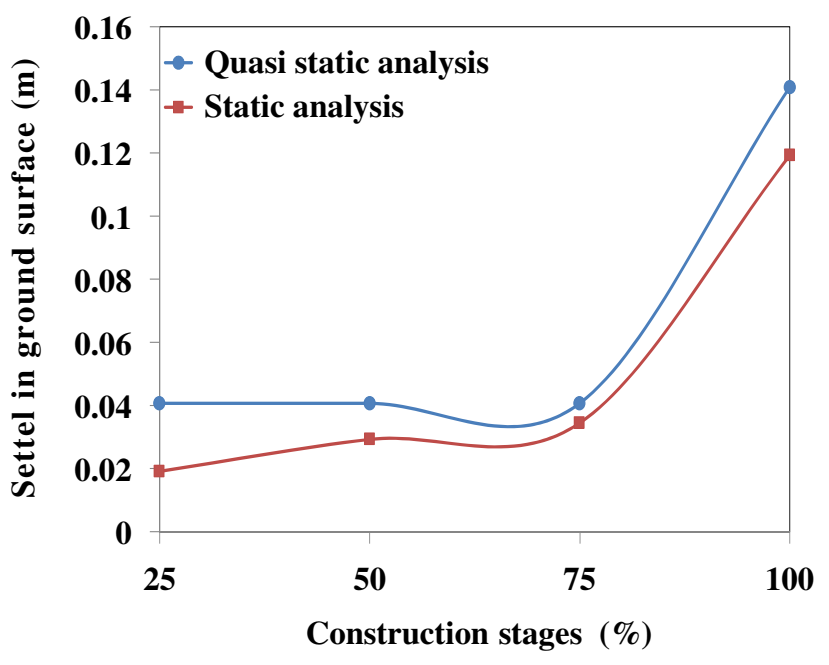

Fig. 31 Effect of change in construction stages on the settle in the ground surface

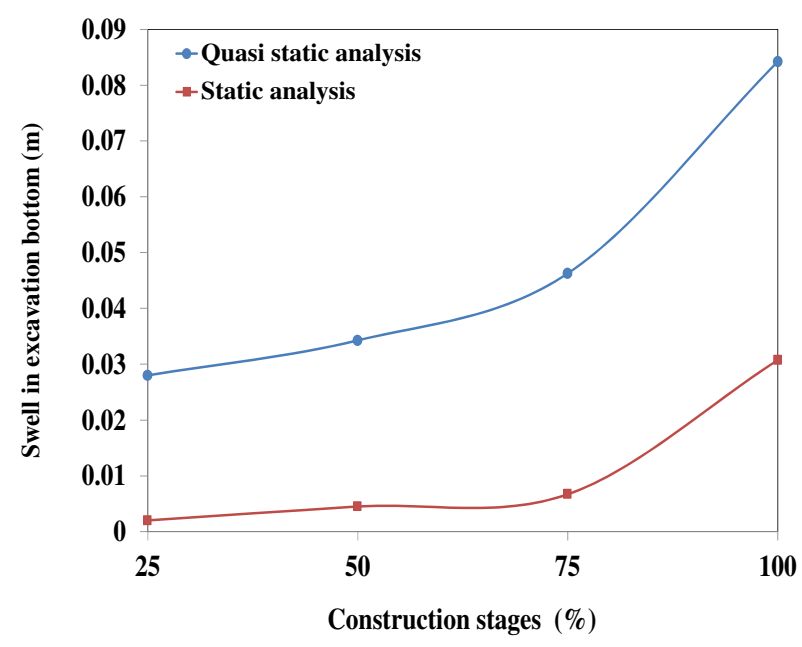

Fig. 32 Effect of change in construction stages on the swell in the excavation bottom

one of these methods. If the design of the truss guardian structure permanently is performed, the criteria of seismic design should be considered to control the excavation located behind it and the quasi-static analyzes for the stability of excavation should be performed. This indicates the importance of quasi-static analysis in the excavations that are permanently executed by the truss guardian structure method compared to the temporary excavation performed by static analysis in the excavation restrained by the truss guardian structure method.

The parametric study was previously presented and independently discussed; however, further overall discussion is required as follows: 
The present study has been considered as a case study that it has different conditions from previous researches in terms of soil geotechnical parameters $(c, \phi, E)$ and the height of the trench wall and the characteristics of the guardian structure and the amount of loading as well as the behavioural model for soil.

Therefore, it is not possible to compare the present research in terms of numerical values with the previous researches which those have been performed in the form of the case study and different conditions. Nonetheless, the results of previous researches are in good agreement with the results of the present research, such that the comparison of the present research with the research performed by Fakher and Sabzi [30] which has been performed by finite element method using ABAQUS software, shows that the maximum value the settling on the ground of the building adjacent occur in near the trench wall in the excavation which restrained using the truss guardian structure. Fakher and Sabzi's research [30] showed that by increasing the values of soil strength parameters $(c, \phi, E)$, the values of settling under the building adjacent to the excavation will decrease significantly.

Also, the comparison of the research performed by Fakher and Sabzi [30] with the present study shows a decrease in the horizontal displacement of the trench wall when the soil strength parameters $(c, \phi, E)$ increase which this matter shows the agreement of the results of the present study with the research performed by the above researchers.

\section{Conclusion}

Research work related to the stability and deformation of deep excavation restrained by guardian truss structures system using static already has been done but the seismic analysis of this guardian structures system using the quasi-static approach that is one of the methods seismic analysis has not been seriously considered. For this purpose, a series of 2D finite element parametric studies by static and quasi-static seismic analysis is employed in this study to investigate the effect of influencing parameters on behavior of the excavation restrained by the guardian truss. These parameters include the geotechnical parameters of soil $(c, \phi, E)$ and the geometrical characteristics of the trusses.

Verification of the numerical modeling results is conducted using the results of numerical analyses for the same trench were obtained and compared with the field data measured by the surveying team. In spite of some differences between the results from the two methods, the general trend and variations of the horizontal displacement from top to bottom of the trench are in good agreement and the numerical modeling shows relatively reliable and acceptable results for parametric studies in the present research.

Resulted from the present research show that in both static and quasi-static analyzes, by decreasing the horizontal distance of the trusses, the maximum horizontal displacement of the wall reduced and safety factor will increase and the maximum settling of the adjacent ground and the maximum swelling on the bottom of the trench will decrease.

Results obtained from the numerical modelling in this research for evaluating the performance of deep excavation restrained by guardian truss structures system using static and quasi-static approach showed that choosing suitable values for geotechnical parameters of soil (such as the cohesion, the friction angle and the modulus of elasticity) are effective factors on slope stability and deformation. Improving these geotechnical parameters decrease the maximum horizontal displacement wall trench and the maximum settling of the adjacent ground of the wall trench and the maximum swelling on the bottom of the excavation as a result, the safety factor will increase.

The results reveal that the rate of responses obtained from the quasi-static analysis such as the maximum horizontal displacement and the maximum settling of the adjacent ground and the maximum swelling on the bottom of the trench will be much more than static analysis.

The findings from this research show that by increasing the horizontal seismic acceleration coefficient $\left(K_{h}\right)$, the horizontal force generated by the earthquake in the center of the failure wedge will increase. as a result of, the maximum horizontal displacement of the wall, the maximum settling of the adjacent ground of the wall, the maximum swelling on the bottom of the trench increase and the safety factor will decrease.

The results reveal that as the construction process progresses, the maximum horizontal displacement of the wall and the maximum settling of the adjacent ground of the wall also the maximum swelling on the bottom of the trench increased and the safety factor will decrease.

Generally, the analysis of structures under the influence of earthquakes is mainly based on the quasi-static and dynamic analysis method. The quasi-static method, taking into account the effect of vibrations from the earthquake as vertical and horizontal accelerations and applying vertical and horizontal forces, performs seismic analysis of the structures, but this method has defects in comparison with the dynamic analysis method, One, in a quasi-static method, static forces in a constant direction constantly affect the structure, while the actual seismic forces are cyclic and limited in time and vary with time. These errors make it more preferable to use the dynamic analysis method than the quasi-static method. For this 
purpose, for future research, it is recommended to check the Seismic performance of deep excavation restrained by guardian truss structures system using dynamic numerical analysis performed by applying the acceleration history of an earthquake record to the lower boundary of the finite element numerical model.

Funding The authors received no financial support for the research and/or authorship of this article.

\section{Declarations}

Conflict of interest On behalf of all authors, the corresponding author states that there is no conflict of interest.

Open Access This article is licensed under a Creative Commons Attribution 4.0 International License, which permits use, sharing, adaptation, distribution and reproduction in any medium or format, as long as you give appropriate credit to the original author(s) and the source, provide a link to the Creative Commons licence, and indicate if changes were made. The images or other third party material in this article are included in the article's Creative Commons licence, unless indicated otherwise in a credit line to the material. If material is not included in the article's Creative Commons licence and your intended use is not permitted by statutory regulation or exceeds the permitted use, you will need to obtain permission directly from the copyright holder. To view a copy of this licence, visit http://creativecommons .org/licenses/by/4.0/.

\section{References}

1. Long M (2001) Database for retaining wall and ground movements due to deep excavations. J Geotech Geoenviron Eng 127(3):203-224. https://doi.org/10.1061/ (asce) 1090-0241(2001)127:3(203)

2. Moormann C (2004) Analysis of wall ground movements due to deep excavations in soft soil based on a new worldwide database. Soils Found (JGS) 44(1):87-98. https://doi.org/10.3208/ sandf.44.87

3. Rouainia M, Elia G, Panayides S, Scott P (2017) Nonlinear finiteelement prediction of the performance of a deep excavation in Boston blue clay. J Geotech Geoenviron Eng 143(5):04017005. https://doi.org/10.1061/(ASCE)GT.1943-5606.0001650

4. Castaldo P, De luliis M (2014) Effects of deep excavation on seismic vulnerability of existing reinforced concrete framed structures. Soil Dyn Earthq Eng 64:102-112. https://doi.org/10.1016/j. soildyn.2014.05.005

5. Gaxiola-Camacho JR, Azizsoltani H, Villegas-Mercado FJ, Haldar A (2017) A novel reliability technique for implementation of performance-based seismic design of structures. Eng Struct 142:137-147. https://doi.org/10.1016/j.engstruct.2017.03.076

6. Maleki M, M.M.H Majdeddin (2020) Seismic performance of deep excavations restrained by anchorage system using quasi static approach. http://www.jsee.ir/article_240810.html

7. Bayoumi A, Bobet A, Lee J (2008) Pullout capacity of a reinforced soil in drained and undrained conditions. Finite Elem Anal Design 44:525-536. https://doi.org/10.1016/j.finel.2008.01.009
8. Fellenius, W (1936) Calculation of stability of earth dams, Transactions. 2th International congress on Large dams, Int Commiss Large Dams 445-449

9. Jian YSS (1990) Analysis using boundary elements. Springer, New York

10. Matsui T, San K (1992) Finite element slope stability analysis by shear strength reduction technique. Soil Found 32:59-70. https ://doi.org/10.3208/sandf1972.32.59

11. Griffiths DV, Lane PA (1999) Slope stability analysis by finite elements. Geotechnique 49:387-403. https://doi.org/10.1680/ geot.1999.49.3.387

12. Leong EC, Rahardjo H (2012) Two and three-dimensional slope stability reanalyses of Bukit Batok slope. Comput Geotech 42:81-88. https://doi.org/10.1016/j.compgeo.2012.01.001

13. Li LC, Tang CA, Zhu WC, Liang ZZ (2009) Numerical analysis of slope stability based on the gravity increase method. Comput Geotech 36:1246-1258. https://doi.org/10.1016/j.compg eo.2009.06.004

14. Ji J, Liao HJ, Low BK (2012) Modeling 2-D spatial variation in slope reliability analysis using interpolated autocorrelations. Comput Geotech 40:135-146. https://doi.org/10.1016/j.compg eo.2011.11.002

15. Jaritngam, S., Chuchom, S., Limsakul, C., Jaritngam, R (2001) Slope stability analysis using neural networks. The 6th Mining, Metallurgical and Petroleum Engineering Conference on Resources Exploration and Utilization for Sustainable Environment (REUSE), Bangkok, Thailand, 24-26

16. Peck, R. B (1969) Deep excavations and tunnelling in soft ground Proceeding, 7th International Conference on Soil Mechanics, Sociedad Mexicana de Mecanica de Suelos, Mexico City 225-290.

17. Clough, G. W., and O'Rourke, T. D (1990) Construction induced movements of in situ walls. Proc., Conf. on Design and Performance of Earth Retaining Structures 15: 439-470.

18. Puller M (2003) Deepexcavations: a practical manual, 2nd edn. Thomas Telford, London

19. Chang CY, Duncan JM (1970) Analysis of soil movement around a deep excavation. Proc ASCE 96(5):1655-1970

20. Burland JB, Hancock RJR (1977) Underground car park at the house of commons. London Struct Eng 55(2):87-100

21. Simpson B, O'Riordan NJ, Croft DD (1979) A computer model for the analysis of ground movements in London Clay. Géotechnique 29(2):149-175

22. Powrie W, Batten M (2000) Comparison of measured and calculated temporary proploads at Canada water station. Géotechnique 50(2):127-140. https://doi.org/10.1680/ geot.2000.50.2.127

23. Plaxis 2D (2017) Reference manual. Delft, Netherlands

24. Brinkgreve, R. B. J. (2005) Soil Constitutive Models-Selection of Soil Models and Parameters for Geotechnical Engineering Application, Engineers Geo-Frontiers Congress 2005 - Austin, Texas, United States ASCE. 69-97. https://doi.org/10.1061/40771(169)4

25. Bolton MD (1986) The strength and dilatancy of sands. Geotech J Geotech Eng, Geotech 36:65-78. https://doi.org/10.1680/ geot.1986.36.1.65

26. Peng FL et al (2011) Field measurements and finite-element method simulation of a tunnel shaf constructed by pneumatic caisson method in shanghai soft ground. J Geotech Geoenviron Eng 137:516-524. https://doi.org/10.1061/(ASCE)GT.19435606.0000460

27. Potyondy JG (1961) Skin friction between various soils and construction materials. Geotech J Geotech Eng, Geotech 11:339353. https://doi.org/10.1680/geot.1961.11.4.339 
28. Lees A (2016) Geotechnical finite element analysis. ICE Publishing, London

29. Ashrafi H. )(2019) Principles of excavation and Guard Structures, 2nd Ed, Iran, no avar.

30. Sabzi1 z, Fakher A. (2015) The performance of buildings adjacent to excavation supported by inclined struts. International Journal of Civil Engineering, 13: 1-15 URL: http://ijce.iust.ac.ir/article1-935-en.html

Publisher's Note Springer Nature remains neutral with regard to jurisdictional claims in published maps and institutional affiliations. 